\title{
INFORMAÇÕES SOBRE A REVISTA CIENTÍFICA AREL FAAr - Amazon's Research and Environmental Law
}

\section{MISSÃO}

A Revista é de titularidade do Instituto de Ensino Superior de Rondônia/Faculdades Associadas de Ariquemes - IESUR/FAAr. Sua missão é disseminar estudos e pesquisas inéditas realizadas na área do Direito, estabelecida em dezembro do ano de 2012, após aprovação no Conselho Superior do IESUR/FAAr (CONSUP).

\section{OBJETIVOS DA REVISTA}

O objetivo da Revista AREL - Amazon's Research and Environmental Law é a a interrelação entre a ciência e a prática jurídica, em face da formação integral dos profissionais da área. Para efetivar o seu objetivo, buscam-se articulistas e/ ou pesquisadores que investiguem as possíveis formas em que o Direito possa contribuir para a edificação da consciência social e a formação de valores em face das novas relações estabelecidas entre a Sociedade e o Estado.

\section{LINHA EDITORIAL}

Projeta o desenvolvimento de estudos históricos, comparados e contemporâneos, através de duas linhas de pesquisa:

Linha de Pesquisa I - Sociedade, Empresa e Sustentabilidade.

Discutem-se as perspectivas de desenvolvimento empresarial, procurando novas formas de efetivação do desenvolvimento econômico-social e ambiental.

Linha de Pesquisa II - Direitos Fundamentais e suas dimensões.

\footnotetext{
1'Disponível em: <http://www.faar.edu.br/portal/revistas/ojs/index.php/arel-faar/index>. Acesso em 05 mai. 2013.
} conhecimento científico ao público proporciona maior democratização mundial do conhecimento. Adota a licença Creative Commons (atribuição - uso não comercial - não a obras derivadas: by-nc-nd). Utiliza o Open Journal Systems, sistema de código livre gratuito para a administração e a publicação de revistas, desenvolvido com suporte e distribuição pelo Public Knowledge Project sob a licença GNU General Public License. 
Estudam-se as correlações e contribuições possíveis entre os Direitos Fundamentais e a realização da cidadania.

A linha editorial desenvolvida pela Revista, por vezes, busca o vértice comum entre as duas linhas de pesquisa. Nesses casos, busca discutir: os aspectos fenomenológicos da empresa e as características da sociedade onde se insere; e os efeitos da ineficácia social do Direito, a exclusão social e jurídica e a relação à dignidade da pessoa humana com a sustentabilidade, procurando contribuir de alguma forma para as discussões científicas em torno do exercício do poder político e da Justiça.

\section{FORMATO DOS NÚMEROS DA REVISTA}

Todos os números deverão publicar, no mínimo, cinco artigos científicos, que versem sobre as linhas de pesquisa: I - Empresa, sociedade e sustentabilidade; II - Direitos Fundamentais e suas dimensões, ou o seu cruzamento.

A Revista prioriza a publicação de textos científicos inéditos, a saber: artigos científicos, resenhas e análise de jurisprudências ${ }^{2}$. A Revista é disponibilizada na plataforma OJS, de forma a facilitar aos leitores o acesso ao seu conteúdo.

\section{PROCEDIMENTOS PARA PUBLICAÇÃO OU DIRETRIZES AOS AUTORES}

A Revista Científica AREL FAAr - Amazon's Research and Environmental Law, ISSN n. 2317-8442, recebe ARTIGOS NACIONAIS E ESTRANGEIROS, RESENHAS e ANÁLISE DE JURISPRUDÊNCIAS, com as seguintes característica:

\section{Redação - Diretrizes básicas}

1.1. A redação da produção bibliográfica, quando em nosso Idioma, deve estar conforme as regras do novo Acordo Ortográfico da Língua Portuguesa e quando em língua inglesa deve estar em conformidade com as respectivas regras ortográficas;

1.2. As produces bibliográficas podem ser publicados em português ou inglês.

\footnotetext{
${ }^{2} \mathrm{~A}$ Revista pode publicar, se houve interesse científico institucional: resumo de teses e dissertações; traduções de textos não disponíveis em língua portuguesa; relatórios de pesquisa, na forma de Empirical Research Review, estudos estatísticos ou estudo de casos; debates científicos; comentários jurídicos; transcrição de palestras, e outros relevantes à área do Direito, desde que seja regulamentado o modus operandi.
} 
1.3. As referências nacionais ou estrangeiras devem ser consistentes e mostrar o posicionamento dos doutrinadores sobre o tema.

\section{Elementos estruturadores básicos}

2.1. Os artigos deverão ser inéditos e atuais, escritos em português ou inglês, e atender ao seguinte conteúdo e nesta ordem: título, título em inglês, resumo (em português), palavras-chave, abstract (resumo em inglês), keywords (palavras -chaves em inglês), introdução (não deve vir numerada), desenvolvimento (dividido em itens numerados), considerações finais (não deve vir numerada) e referências (não numerada e em ordem alfabética);

2.2. O título do artigo deve estar em português e em inglês), centralizado na página, com letra maiúscula e em negrito - fonte 16;

2.2.1. Os subtítulos, quando existirem, devem ser concisos e vir claramente indicados - fonte 12;

2.3. Os capítulos, subcapítulos e demais subdivisões do artigo devem estar em letras minúsculas, em negrito, numerados de forma progressive - fonte 12 .

2.4. O artigo deve conter 'Resumo' em português e 'Abstract' em inglês, ressaltando no conteúdo do texto os objetivos, a metodologia e a síntese das considerações finais. Fonte times new roman, corpo 11, espaçamento simples $(1,0)$, máximo de 200 palavras;

2.5. O artigo deve indicar de três a cinco palavras-chave, podendo conter expressões representativas do tema, em português, inglês e no idioma de origem, se for o caso, refletindo as ideias elementares do texto e que possam auxiliar a pesquisa de terceiros interessados.

2.6. As RESENHAS poderão ser críticas ou descritivas de obras na lingual portuguesa ou inglesa sobre temas pertinentes às linhas de pesquisa da Revista.

2.6.1. Deverão ser inéditas e atuais, escritas em português ou inglês, e atender ao seguinte conteúdo e nesta ordem: nome resenha em português e inglês, título em português ou inglês da obra em análise, elaboração de texto no format dissertação contend: introdução, desenvolvimento e conclusão em texto corridor, podendo ter ou não referências (não numerada e em ordem alfabética); deve indicar as palavras-chave da obra analisada.

2.6.2. O título da obra deve estar no alinhamento justificado e na forma apresentada na ficha catalográfica da obra analisada. 
2.7. As ANÁLISES DE JURISPRUDÊNCIAS deverão atender ao seguinte conteúdo e nesta ordem: título, título em inglês, resumo (em português), palavras-chave, abstract (resumo em inglês), keywords (palavras-chaves em inglês), introdução (não deve vir numerada), desenvolvimento (apresentando e analisando os julgados), considerações finais (não deve vir numerada) e referências (não numerada e em ordem alfabética);

2.7.1. O título da análise de jurisprudências deve estar em português e inglês (conforme o caso), centralizado na página, com letra maiúscula e em negrito fonte 16;

\section{Outras regras de formatação}

3.1. Os artigos devem ter no mínimo 10 e no máximo de 30 páginas;

3.2. As resenhas e as análise jurisprudenciais devem ter no mínimo 2 e no máximo 10 páginas;

3.3. Os artigos, as resenhas e as analyses de jurisprudências devem ser digitados no editor de texto Microsoft Word, em formato A4 $(21,0 \times 29,7 \mathrm{~cm})$, posição vertical, fonte Times New Roman, corpo 12; alinhamento justificado (sem separação de sílabas), com espaçamento entre linhas de $1,5 \mathrm{~cm}$;

3.4. O Layout da página deve ter margens superior e inferior de $2,5 \mathrm{~cm}$ e margens esquerda e Direita de $3,0 \mathrm{~cm}$;

3.5. 0 parágrafo deve ter espaçamento posterior e anterior de 0 ponto. 0 recuo dos parágrafos deve ter $1,25 \mathrm{~cm}$;

3.6. Quando for necessária a utilização de siglas e abreviaturas, estas deverão ser introduzidas entre parênteses, logo após o emprego do referido termo na íntegra quando do seu primeiro aparecimento no texto. A partir da primeira menção o autor poderá utilizar somente a sigla ou abreviatura. As siglas e abreviaturas inseridas em tabelas ou ilustrações devem possui definição nas suas respectivas legendas.

\section{Referências, Notas e Citações}

4.1. As referências deverão conter todos os dados necessários à identificação das obras e estar em ordem alfabética da primeira letra do Sobrenome do Autor e constar em lista não numerada no final do artigo. No artigo o item deve ser de- 
nominado "Referências", seguindo as normas vigentes da Associação Brasileira de Normas Técnicas (ABNT - NBR 6023 - Informação e Documentação - Referências - Elaboração. / Ago. 2002);

4.1.1. As referências de obras e documentos consultados devem ser feitas apenas se efetivamente tiverem sido citadas no artigo, uniformizadas, seguindo as normas vigentes da ABNT;

4.2. As citações bibliográficas devem ser feitas de acordo com as normas da ABNT (NBR 10520 - Informação e Documentação - Citações em documentos - Apresentação/ Ago. 2002), adotando-se preferencialmente o sistema autor-data.

4.2.1. Se houver mais de uma obra do mesmo autor citado no mesmo ano, devem ser utilizadas letras para distingui-los. Exemplo: Nunes (2013a). A organização alfabética será a do nome dos artigos ou obras do autor naquele mesmo ano.

4.3. As notas não bibliográficas devem ser colocadas no rodapé, utilizando-se de fonte tamanho 10, ordenadas por algarismos arábicos que deverão aparecer imediatamente após o segmento do texto ao qual se refere a nota.

4.4. Os artigos submetidos que contiverem partes de texto extraídas de outras publicações deverão obedecer aos limite de 200 palavras para garantir originalidade do trabalho submetido. Recomenda-se evitar a reprodução de tabelas e ilustrações extraídas de outras publicações. 0 artigo que contiver reprodução de uma ou mais tabelas e/ou ilustrações de outras publicações deverá ser encaminhado para análise acompanhado de permissão escrita do detentor do direito autoral do trabalho original endereçada ao autor, especialmente para o artigo submetido à Revista;

4.5. As citações textuais pequenas (de até três linhas) deverão ser inseridas no corpo do artigo, entre aspas duplas e sem itálico. As citações textuais longas (com mais de três linhas) devem ser destacadas em parágrafo independente com recuo de $4 \mathrm{~cm}$ da margem esquerda, com corpo 11 , com o espaçamento simples, sem aspas.

\section{Submissão}

5.1. Os artigos, resenhas e analises de jurisprudências devem ser submetidos a revisão de linguagem e digitação, e, constar a data de sua elaboração antes de serem encaminhados para a Revista.

5.2. Cada autor (individualmente ou em coautoria) poderá submeter apenas um artigo por ano na Revista; 
5.2.1. A coautoria é limitada ao máximo de dois autores;

5.3. $O$ arquivo submetido pelo autor (Artigos Nacionais ou Estrangeiros, Resenhas e Análise Jurisprudenciais) deve ser apresentado sem a identificação do(s) autor(es) no corpo do trabalho.

5.4. Em arquivo apresentado na plataforma OJS, junto com a autorização expressa para publicação, os autores de textos (individuais ou em coautoria) deverão indicar, o nome completo, o nome e a sigla da instituição a qual estão ligados, cidade, estado, país, cargo, endereço eletrônico para correspondência (e-mail), bem como o endereço completo e telefones de contato.

5.5. 0 arquivo submetido não poderá estar sob avaliação para publicação em outro periódico e nem durante o processo de avaliação da Revista, sob pena de ser desclassificado.

5.6. Os artigos assinados são de responsabilidade exclusiva dos autores. 0 conteúdo do artigo assinado não reflete a opinião da Revista;

5.7. No momento da submissão da produção bibliográfica à Revista, haverá a concordência da declaração de cessão de direitos autorais na plataforma OJS.

5.8. Os envios dos trabalhos serão considerados participações voluntárias e gratuitas dos autores, com os direitos autorais cedidos para a Revista.

5.9. Os autores devem preencher as condições de submissão especificadas nestas diretrizes para terem os seus trabalhos avaliados.

5.10. Os autores serão notificados sobre o resultado da avaliação de seus artigos ou resenhas através de e-mail.

5.11. As submissões que não estiverem de acordo com as normas serão devolvidas aos autores para as devidas retificações antes do processo de avaliação.

5.12. A produção bibliográfia para publicação na Revista pode ser submetida em fluxo contínuo ou atendendo as datas especificadas pela CHAMADA DE PUBLICAÇÃO.

\section{NORMAS PARA A APRESENTAÇÃO DE TRABALHOS À REVISTA OU PARA A SUBMISSÃO ON LINE}

Como parte do processo de submissão, os autores são obrigados a verificar a conformidade da submissão em relação a todos os itens listados acima (procedimentos para publicação ou diretrizes aos autores) e declararão em formulário eletrônico na plataforma OJs que: 
1. A contribuição é original e inédita, e naõ foi publicado em anais de congress, seminaries, colóquios ou similares e não está sendo avaliada para publicação por outra revista; caso contrário, deverá justificar em "Comentários ao editor".

2. 0 arquivo da submissão está em formato Microsoft Word ou RTF.

3. Os URLs para as referências foram informadas, quando possível.

4. 0 texto segue os padrões de estilo e requisitos bibliográficos descritos em Diretrizes para Autores, na página Sobre a Revista.

5. As instruções de anominato do arquivo submetido para assegurar a avaliação Double Blind Peer Review foram seguidas.

6. A Declaração de Direito Autoral, contendo a AUTORIZAÇÃO DE PUBLICAÇÃO E CESSÃO DE DIREITOS AUTORAIS.

7. A concessão não terá caráter de ônus para o Conselho Editorial da Revista. Ou seja, não haverá pagamento pela utilização do referido material, tendo a possível publicação o caráter de colaboração. 0 autor compromete-se a assegurar o uso e gozo da obra à Revista, que poderá explorá-la com exclusividade nas edições que fizer.

8. 0 autor tem ciência de que:

a) A publicação desta obra poderá ser recusada, caso o Conselho Editorial da Revista, não considere conveniente sua publicação, seja qual for o motivo. Este cancelamento não acarretará responsabilidade a qualquer título por parte do Conselho Editorial; e

b) Os editores, juntamente com o Conselho Editorial, reservam-se o direito de modificar o texto - quando necessário, sem prejudicar o conteúdo -, com o objetivo de uniformizar a apresentação dos materiais publicados.

\section{PROCEDIMENTOS UTILIZADOS PARA ANÁLISE E APROVAÇÃO DOS ARTIGOS (DOUBLE BLIND PEER REVIEW) NA REVISTA}

\section{Procedimentos de avaliação}

1.1. Todas as produções serão avaliadas pelo sistema Double Blind Peer Review, salvo as submissões que não estiverem de acordo com as normas de publicação ou diretrizes aos autores, que serão devolvidas para as devidas retificações antes de iniciar o procedimento de submissão aos avaliadores.

1.2. Todos os arquivos serão analisados por 02 (dois) pareceristas externos ad 
hoc, bem como pelo Conselho Editorial. E, em caso de controvésia, haverá análise de um terceiro parecerista "ad hoc".

1.2.1 Todos os pareceristas e conselheiros pertencentes à Revista são professores doutores.

1.3. Os pareceres emitidos pelos pareceristas "ad hoc" são elaborados no formato do formulário disponibilizado na Revista dentro da página das "Diretrizes aos Autores", disponível no endereço: <http://www.faar.edu.br/portal/revistas/ ojs/index.php/arel-faar/manager/previewReviewForm/1>.

1.3.1. Na avaliação dos pareceristas "ad hoc" são observados os seguintes critérios:

a) Fundamentação teórica e conceitual adequada ao tema escolhido;

b) relevância e pertinência e atualidade no tema objeto do artigo;

c) consistência metodológica de pesquisa e o cumprimento da lista de diretrizes aos autores - normas da ABNT e das normas específicas da Revista; e

d) formulação do artigo em linguagem correta, clara e concisa seja em língua portuguesa seja em língua estrangeira.

1.3.2. Ao final, da avaliação será apontado se a produção bibliográfica será:

a) aceita sem restrições;

b)aceita com proposta de alteração; e

c) rejeitada.

1.4 A decisão dos pareceristas "ad hoc" escolhidos pelo Conselho Técnico Científico, especialmente o Editor Chefe ou o Editor Adjunto será submetida ao Conselho Editorial para referendo ou não.

1.4.1 A decisão do Conselho, em colegiado, será por decisão majoritária dos presentes, com o quorum mínimo será de dois conselheiros, que não for o Presidente do Conselho Editorial, pois the é vedado votar na reunião do colegiado.

1.4.2. A convocação da reunião do Conselho Editorial é realizada por e-mail pelo Presidente do Conselho Editorial, obrigatoriamente 15 dias antes de sua realização.

1.4.3. A reunião do Conselho Editorial poderá ser realizada nas dependências do IESUR/FAAr ou no ambiente virtual, por meio da ferramenta de vídeo ou teleconferência do "Skype", software criado em 2003 que permite a conexão de pessoas em rede.

1.4.3.1. Os termos da ata da reunião do Conselho poderão ser trancritos ou 
gravados, conforme a decisão do Presidente do Conselho, ao qual compete a relatoria da reunião.

1.4.4. O colegiado com os Conselheiros presentes decidirá quais os artigos submetidos e avaliados pelos pareceristas "ad hoc" para o número do volume da Revista estão de acordo com a missão, os objetivos da Revista e a linha editorial, além de conferir se:

a) o autor preencheu o termo de aceitação das normas da Revista, declarando não ter apresentado o artigo, na íntegra, em nenhum outro veículo de informação nacional ou internacional; a declaração de cessão de direitos autorais, ambas apresentadas no sistema OJS, no momento da submissão; e

b) se houver necessidade, se há a emissão de autorização ou declaração de direitos cedidos por terceiros, caso reproduza figuras, tabelas ou texto no percentual de mais de 200 palavras de obra publicada no sistema OJS, no momento da submissão.

1.4.4. Após as deliberações, para cada artigo submetido e previamente avaliado pelos parecerietas “ad hoc”, três decisões podem ser emitidas pelo Conselho Editorial da Revista, gerando os seguintes efeitos:

a) “Aceitação sem restrição" - o Editor Chefe ou o Editor Adjunto comunicará a decisão ao autor, por e-mail, preferencialmente, no prazo de 30 dias após a submissão do artigo à Revista Científica. Na comunicação será juntado um resumo do teor das decisões dos pareceristas "ad hoc" e do Conselho Editorial;

b) “Aceitação com proposta de alteração", o Editor Chefe ou o Editor Adjunto comunicará a decisão ao autor, por e-mail, preferencialmente, no prazo de 30 dias após a submissão do artigo à Revista Científica. Na comunicação será juntado o teor dos pareceres tanto dos pareceristas "ad hoc" quanto do Conselho Editorial, incluindo as propostas de alterações ou qualquer outra sugestão cabível a melhoria do conteúdo e da forma do artigo, preservando o anonimato. b.1) Os arquivos que necessitarem de modificações serão devolvidos aos autores, com as respectivas sugestões para alteração.

b.2) As alterações solicitadas são de responsabilidade exclusiva do autor e serão novamente submetidas aos pareceristas "ad hoc" que sugeriram as propostas de alterações.

c) “Rejeição", o Editor Chefe ou o Editor Adjunto comunicará a decisão ao autor, por e-mail, preferencialmente, no prazo de 30 dias após a submissão do artigo à Revista Científica. Na comunicação será declarado o não interesse em publicar, preservando o anonimato. 
c.1) A Revista reserva-se o direito de não avaliar e rejeitar ad nutum os trabalhos enviados fora da linha editorial.

1.5. Havendo a submissão de produção bibliográfica por qualquer parecerista "ad hoc" ou membro do Conselho Editorial ou do Conselho Técnico Científico, será vedada a participação do autor em qualquer ato interno do número da Revista, sob pena de declassificação por conflito de interesse.

\section{Publicação}

2.1. Após o processo de avaliação, serão publicados as producões bibliográficas que forem aprovadas pelos pareceristas "ad hoc" e referendadas pelo Conselho Editorial, em colegiadopor voto da maioria dos presentes.

2.2. Se a produção bibliográfica for aceita para publicação, a mesma será publicada com a identificação do autor próximo ao título quanto a sua titulação e filiação institucional e em nota-de-rodapé, constará o nome e a sigla da instituição a qual está ligado, cidade, estado, país, cargos e demais atuações do autor, além do endereço eletrônico para correspondência (e-mail).

\section{CHAMADA PÚBLICA PARA PÚBLICAÇÃO NO NÚMERO 2 VOLUME 2 DA REVISTA AREL FAAr}

Embora a Revista Científica AREL FAAr - Amazon's Research and Environmental Law, ISSN n. 2317-8442, seja de fluxo contínuo, o seu Conselho Editorial, está recebendo artigos para o número 2 volume 2 , que serão publicados em maio deste ano.

Os interessados devem submeter seus artigos até o dia 20 de março de 2014 pelo endereço: http://www.faar.edu.br/portal/revistas/ojs/index.php/arel-faar/about/submissions\#onlineSubmissions.

Os artigos deverão estar em conformidade com as normas da Associação Brasileira de Normas Técnicas (ABNT) e as regras específicas da Revista apresentadas no endereço: http://www.faar.edu.br/portal/revistas/ojs/index.php/arel-faar/ about/submissions\#onlineSubmissions. 